\title{
In vitro Release Kinetics Study of Diltiazem Hydrochloride from Pellets using an Ethylcellulose Pseudolatex Coating System
}

\author{
Golam Kibria and Reza-ul J alil \\ Department of Pharmaceutical Technology, Faculty of Pharmacy, \\ University of Dhaka, Dhaka-1000, Bangladesh
}

\begin{abstract}
In the present study an attempt has been made to investigate the effect of ethylcellulose as a rate retarding material to sustain the release of diltiazem hydrochloride from pellets prepared by air suspension technique. Aqueous ethylcellulose dispersion (Surelease) with different weight ratios was chosen to sustain the release of the drug. Drug was loaded on dummy seeds by following matrix system as well as barrier coating system. The comparative study of this two manufacturing processes was also the goal of this study. In vitro dissolution studies were carried out using USP dissolution apparatus Type-2. The release of drug was faster from matrix system than that of barrier coating system. About $100 \%$ drug was released within 3 hours with $5 \%$ polymer load from both systems. While the polymer content was $10 \%$, about $4 \mathrm{~h} \& 7 \mathrm{~h}$ required for $50 \%$ \& $80 \%$ drug release respectively from barrier coating system. The effect of ethylcellulose on the release of diltiazem hydrochloride was found to be predominant in barrier coating system than that of the matrix system. In the matrix system the drug comes to dissolution media easily and water soluble additives form channel very fast. The kinetic study of the drug was performed and it was revealed that the release of drug from pellets appeared to follow zero order kinetics.
\end{abstract}

Key words: Diltiazem, Pellets, Pseudolatex, Aqueous coating, Manufacturing process, Release kinetics.

\section{INTRODUCTION}

Traditionally, the word "pellet" has been used to describe a variety of systemically produced, geometrically defined agglomerates obtained from diverse starting materials utilizing different processing conditions. Pelletization is an agglomeration process that converts fine powders or granules of bulk drugs and excipients into small, freeflowing, spherical or semi-spherical units referred to as pellets. ${ }^{1}$ Pellet-based extended-release products initially employed conventional pills. Pills of different release profiles were combined in predetermined proportions and encapsulated in hard

Correspondence to: Reza-ul Jalil

Tel: 880-2-9661900-73 (Ext-8179), Fax: 88-02-8615583

E-mail: raju1559@yahoo.com gelatin capsules to produce sustained-release oral dosage forms. A major break through occurred in 1949 when a pharmaceutical scientist at Smith Kline \& French (SK \& F, UK) realized the potential application of candy seeds in sustained-release preparations and embarked on the development of tiny drug pellets that could be loaded into capsules. ${ }^{2}$ However in 1951 a landmark paper, which described in detail the manufacturing process of the seeds, appeared in the Confectioners Journal and revolutionized the production of pelletization products. This process utilized standard coating pans and involved successive layering of powder and binder on sugar granules until spherical seeds of the desired size were obtained. ${ }^{3,4}$ 
In this study diltiazem hydrochloride has been used as a model drug and commercial aqueous ethylcellulose dispersion (Surelease, 25\% w/w dispersion) is used as modified release polymeric material. Diltiazem, a benzothiazepine, is a calcium antagonist, inhibiting calcium ion entry into smooth muscle cells by blockade of slow calcium channels. Ethylcellulose is widely used in oral and topical pharmaceutical formulations. ${ }^{5,6}$ The main use of ethylcellulose in oral formulations is as a hydrophobic coating agent for tablets and granules. ${ }^{7-}$

${ }^{11}$ Ethylcellulose coatings are used to modify the release of a drug ${ }^{12-14}$ to mask an unpleasant taste or to improve the stability of a formulation, as is the case where granules are coated with ethylcellulose to inhibit oxidation. Ethylcellulose, dissolved in an organic solvent or solvent mixture, can be used on its own to produce water-insoluble films. Ethylcellulose films may also be modified to alter their solubility ${ }^{15}$, by the addition of hydroxypropylmethylcellulose ${ }^{16-18}$ or a plasticizer. ${ }^{19}$ An aqueous polymer dispersion (or latex) of ethylcellulose such as Surelease may also be used to produce ethylcellulose films without the need for organic solvents. Drug release through ethylcellulose-coated dosage forms can be controlled by diffusion through the film coat. This can be a slow process unless a large surface area (e.g., pellets or granules vs tablets) is utilized. In those instances, aqueous ethylcellulose dispersions tend therefore to be used to coat granules or pellets. ${ }^{20-21}$

\section{MATERIALS AND METHODS}

Materials used in this experiment are Diltiazem Hydrochloride (Index Pharma, India), Sucrose (Cerestar, Netherland), Lactose (The Lactose Co. of Newzealand Ltd. Newzealand), Maize Starch (Cerestar, Netherland), Polyethylene Glycol (PEG 6000) (Cell Chemical Co. Korea), Kollidon 30 (BASF, Germany), Surelease (Colorcon, Germany), Hydroxypropylmethylcellulose (HPMC 6 cps) (Shinetsu, Japan). All the other chemicals used were of analytical grade.

Preparation of Diltiazem Hydrochloride sustained release pellets. For the preparation of diltiazem hydrochloride SR pellets, all the required materials were passed through 180 micron SS screen except Kollidon 30, PEG 6000, Sucrose, HPMC 6 cps and the liquids. Powder layering method was chosen to prepare the nonpareil seeds (NPS) with sucrose, lactose, maize starch, Kollidon 30 and water in the Centrifugal Fluidized Coater. After completion of the process, seeds were dried at 65-70 degree $\mathrm{C}$ for 6-7 hours in hot air oven and sieved through 18 \& 25 mesh to get 18/25 size pellets.

The air suspension technique was used to prepare the diltiazem hydrochloride sustained release pellets. Different proportions of ethylcellulose i.e. 5\%, 10\%, $15 \%$ \& $20 \%$ (\%w/w on dry basis) with reference to total weight of pellets were taken for drug loading or coating to prepare the following samples.

a) Method 1: Matrix system. Hydroxypropylmethylcellulose (HPMC 6 cps) and diltiazem hydrochloride were dissolved separately in purified water and mixed. PEG 6000 was added to this \& dissolved. $5 \%$ of Surelease (\%w/w on dry basis) was added to the solution and diluted with purified water to make the final weight of solution according to table 1. 215.00 g NPS was loaded onto the bottom spray fluid bed coater (Wurster column) and the drug-polymer mixture was sprayed. After completion of spraying, the coated pellets were dried at $55-60{ }^{0} \mathrm{C}$ for 6 hours in hot air oven (Tray drier) and sieved through $16 \& 22$ mesh to get $16 / 22$ size drug loaded pellets and the batch is termed as DSRM-5. Same process was applied for $10 \%, 15 \%$ \& $20 \%$ of Surelease load and the batches were termed as DSRM-10, DSRM-15 \& DSRM-20 respectively (Table 1).

b) Method 2: Barrier coating system. HPMC 6 cps \& diltiazem hydrochloride was dissolve separately in purified water. PEG 6000 was added to HPMC solution then dissolved well. Above two solutions added to each other, mix well \& diluted with purified water to make the final weight of solution mentioned in Table 1. 215.00 g NPS was loaded onto the bottom spray fluid bed coater (Wurster column) and above solution was sprayed. After completion of spraying, the drug loaded pellets 
were dried at $55-60{ }^{0} \mathrm{C}$ for 5 hours in hot air oven (Tray drier). 5\% of Surelease (\%w/w on dry basis) was diluted with purified water to prepare 15\% dispersion from 25\% commercial dispersion then sprayed on the above pellets. After completion of spraying, the coated pellets was dried at $55-60{ }^{0} \mathrm{C}$ for
4.5 hours \& sieved through 16 \& 22 mesh to get $16 / 22$ size barrier coated pellets and the batch is termed as DSRB-5. Same process was applied for $10 \%, 15 \%$ \& $20 \%$ of Surelease load and batches were termed as DSRB-10, DSRB-15 \& DSRB-20 respectively (Table 1).

Table 1. Codes \& formulation of diltiazem hydrochloride sustained release pellets.

\begin{tabular}{|c|c|c|c|c|c|c|}
\hline \multirow[b]{2}{*}{$\begin{array}{l}\text { Formulation } \\
\text { codes }\end{array}$} & \multicolumn{6}{|c|}{ Materials (weights are in g) } \\
\hline & $\begin{array}{l}\text { Non Pareil Seeds } \\
\text { (NPS) }\end{array}$ & *Surelease & Diltiazem $\mathrm{HCl}$ & HPMC 6 cps & PEG 6000 & $\begin{array}{c}\text { Water } \\
\text { upto }\end{array}$ \\
\hline DSRM-5 & 215.0 & 43.0 & 64.25 & 7.0 & 1.0 & 250 \\
\hline DSRM-10 & 215.0 & 86.0 & 64.25 & 7.0 & 1.0 & 300 \\
\hline DSRM-15 & 215.0 & 129.0 & 64.25 & 7.0 & 1.0 & 350 \\
\hline DSRM-20 & 215.0 & 172.0 & 64.25 & 7.0 & 1.0 & 400 \\
\hline DSRB-5 & 215.0 & 43.0 & 64.25 & 7.0 & 1.0 & 250 \\
\hline DSRB-10 & 215.0 & 86.0 & 64.25 & 7.0 & 1.0 & 250 \\
\hline DSRB-15 & 215.0 & 129.0 & 64.25 & 7.0 & 1.0 & 250 \\
\hline DSRB-20 & 215.0 & 172.0 & 64.25 & 7.0 & 1.0 & 250 \\
\hline
\end{tabular}

* 25\% dispersion commercial grade used

In vitro dissolution study. The dissolution of diltiazem hydrochloride sustained release pellets was studied by Erweka (Germany) dissolution tester USP (XXVIII) using USP apparatus 2 (Paddle method). Diltiazem hydrochloride sustained release pellets equivalent to $90 \mathrm{mg}$ of diltiazem hydrochloride was used in $900 \mathrm{ml}$ of dissolution medium (purified water) at $37^{0} \pm 0.5^{\circ} \mathrm{C}$ with a rotation of $100 \mathrm{RPM}$ for 10 hours. Five (5) ml sample was drawn after $1 / 2$ hour then at every one-hour interval and replaced with the fresh medium to maintain the sink condition. After dilution, the drug content was determined by spectrophotometric method at $237 \mathrm{~nm}$ by using UVVisible Spectrophotometer (Shimadzu, Japan). Drug dissolved at specified periods was plotted as percent release versus time (hours) curve.

\section{RESULTS AND DISCUSSION}

Diltiazem hydrochloride was loaded either with HPMC \& surelease onto non-pareil seeds as matrix system or loaded along with HPMC onto non-pareil seeds then finally barrier coated with aqueous dispersion of ethylcellulose (Surelease) using fluid bed coater. The drug release was studied by in vitro dissolution using USP paddle method.

The release of drug in the dissolution media was found to be a function of the way of drug loading (matrix system or barrier coating system), percent of polymer load as well as the physico-chemical nature of the polymeric materials. From matrix system as well as barrier coating system, it was observed that from all formulations the drug release rate was decreased with gradual increase in ethylcellulose load (Table 2). When diltiazem hydrochloride was loaded with the combination of HPMC 6 cps and different percents of Surelease (5, 10, 15 and 20\% ethylcellulose on dry basis i.e. DSRM-5, DSRM-10, DSRM-15 \& DSRM-20 respectively), it was revealed that from all formulations the release of drug was very high throughout the dissolution process (Figure 1a). In the matrix system, the incorporation of HPMC 6 cps into the coating formulation showed extreme burst release of drug from all formulations at lower percentage of ethylcellulose load (DSRM-5, DSRM10 \& DSRM-15) and some sustaining effect was found only at higher percent of polymer load (DSRM-20). In case of 5\% ethylcellulose load (DSRM-5), about $100 \%$ drug was released from the matrix system within 3 hours, where as for 10\% polymer load (DSRM-10) about 90\% drug was released within 4 hours $\&$ the release was linear only up to 3 hours (Figure 1a). In case of $15 \%$ ethylcellulose load (DSRM-15) the mean dissolution time (MDT) and $\mathrm{T}_{80}$ was $2.61 \mathrm{~h}$ and $4.93 \mathrm{~h}$ respectively (Table 2) and drug was released linearly 
through out the whole process $\left(r^{2}=0.9702\right)$. As HPMC 6 cps is highly water soluble \& may act as channel forming agent which may lead to change the solubility characteristics of ethylcellulose ${ }^{16-18}$ in the dissolution media and thus may lead to cause the burst release of drug from all above formulations. Also water soluble plasticizer PEG 6000 may have some role to provide this effect. ${ }^{19}$ Again in the matrix

Table 2. Kinetic parameters of diltiazem hydrochloride release from coated pellets.

\begin{tabular}{|c|c|c|c|c|c|c|c|}
\hline \multirow{2}{*}{$\begin{array}{l}\text { Formulation } \\
\text { codes }\end{array}$} & \multirow{2}{*}{$\begin{array}{c}\%(w / w) \\
\text { polymer } \\
\text { (on dry } \\
\text { basis) }\end{array}$} & \multicolumn{2}{|c|}{ Zero Order } & \multicolumn{2}{|c|}{ Higuchi } & \multirow{2}{*}{$\begin{array}{c}\text { MDT } \\
(\mathrm{Hr})\end{array}$} & \multirow{2}{*}{$\begin{array}{c}\mathrm{T}_{80} \\
(\mathrm{Hr})\end{array}$} \\
\hline & & $\begin{array}{c}\text { Release rate } \\
\text { (\%/time) }\end{array}$ & $r^{2}$ & $\begin{array}{c}\text { Release rate } \\
\left(\% / \text { time }^{-1 / 2}\right)\end{array}$ & $r^{2}$ & & \\
\hline DSRM-5 & 5 & 67.98 & 0.4355 & 58.33 & 0.5943 & 0.74 & 1.73 \\
\hline DSRM-10 & 10 & 20.3 & 0.7662 & 45.28 & 0.8932 & 1.57 & 3.65 \\
\hline DSRM-15 & 15 & 12.54 & 0.9702 & 42.98 & 0.952 & 2.61 & 4.93 \\
\hline DSRM-20 & 20 & 9.89 & 0.9710 & 29.08 & 0.9669 & 4.26 & 6.42 \\
\hline DSRB-5 & 5 & 43.12 & 0.4693 & 76.97 & 0.6318 & 0.91 & 1.81 \\
\hline DSRB-10 & 10 & 10.09 & 0.9871 & 36.96 & 0.9852 & 3.73 & 6.79 \\
\hline DSRB-15 & 15 & 8.76 & 0.9892 & 19.92 & 0.9307 & 5.34 & 8.26 \\
\hline DSRB-20 & 20 & 4.86 & 0.9903 & 14.88 & 0.9562 & 8.87 & 13.7 \\
\hline
\end{tabular}
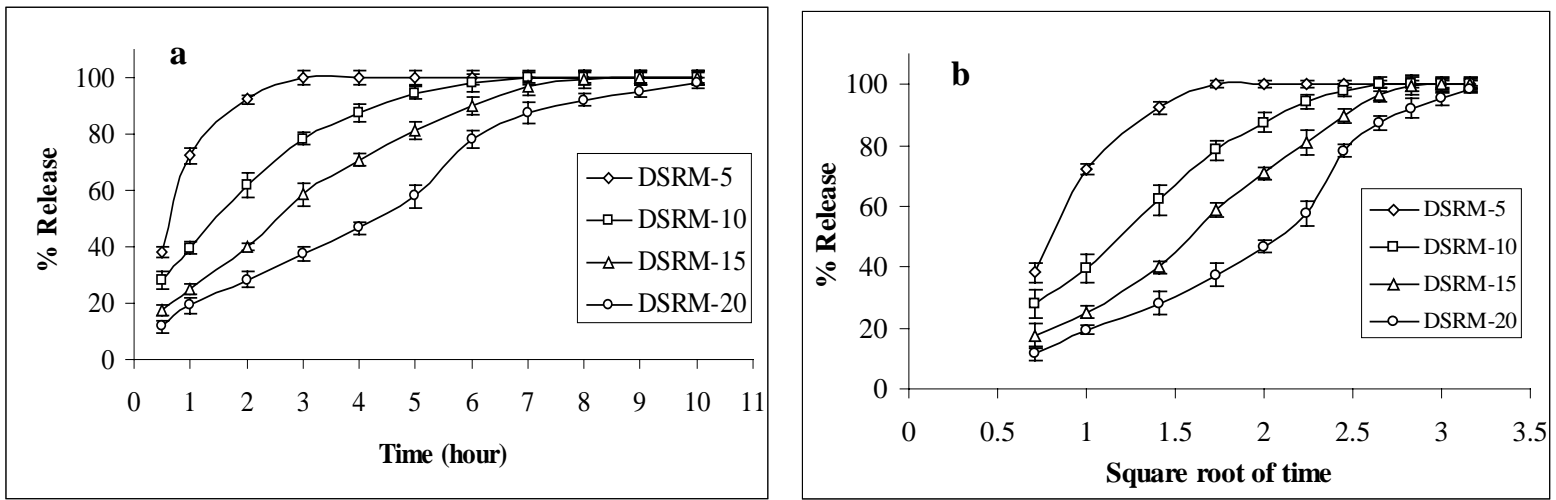

Figure 1. Diltiazem hydrochloride release kinetics from coated pellets when drug is loaded with HPMC \& ethylcellulose (matrix system). [DSRM-5: 5\% ethylcellulose load; DSRM-10: 10\% ethylcellulose load; DSRM-15: 15\% ethylcellulose load; DSRM-20: 20\% ethylcellulose load \& a-Zero order, b-Higuchi plot]

system drug is present at the surface of the pellets along with the coating polymers and due to it's highly water soluble nature during contact in the dissolution media these phenomena may also facilitated the burst release of drug. But in case of $20 \%$ ethylcellulose load (DSRM-20), the MDT value increased to $4.26 \mathrm{~h}$ and in this stage the drug was released in a linear fashion $\left(\mathrm{r}^{2}=0.9710\right)$ up to $5^{\text {th }}$ hour but increased suddenly to $75 \%$ at 6 h (Figure 1a). For higher percentage (20\%) of ethylcellulose load, initially the dissolving rate of HPMC in water was slow hence a linear in drug release was observed up to 5 hours but with the passes of time the maximum amount of HPMC goes into solution and ultimately water penetration rate was increased which ultimately increases the release of drug after a certain time (Figure 1a). Again from Table 2 it was expressed that for $15-20 \%$ polymer load the minimum correlation coefficient value $\left(\mathrm{r}^{2}\right)$ was found 0.9702 which is higher than that of Higuchi's fashion (Figure $1 \mathrm{~b} \&$ Table 2) so it can be said that the release of drug follows zero order release kinetics.

When diltiazem hydrochloride was loaded with the HPMC 6 cps on NPS and barrier coated with different percent of Surelease (5, 10, 15 \& 20\% ethylcellulose on dry basis i.e. DSRB-5, DSRB-10, DSRB-15 \& DSRB-20 respectively), it was revealed that from all formulations the release of drug was 
comparatively lower than those of the formulations of DSRM-5, DSRM-10, DSRM-15 \& DSRM-20 respectively throughout the dissolution process (Figure 2a). In case of 5\% ethylcellulose load (DSRB-5) a burst drug release was found as that of DSRM-5 and about 90\% drug was released within 2 hours which indicates that $5 \%$ polymer is not sufficient enough to form a uniform film around the

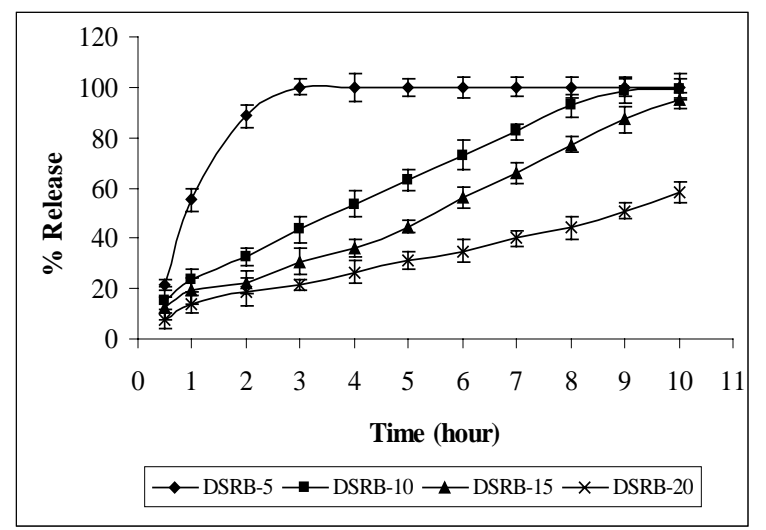

Figure 2. Diltiazem hydrochloride release kinetics from coated pellets when drug is loaded with HPMC then coated with ethylcellulose (barrier coating system). [DSRB-5: 5\% ethylcellulose load; DSRB-10: 10\% ethylcellulose load; DSRB-15: 15\% ethylcellulose load; DSRB-20: 20\% ethylcellulose load \& a-Zero order, b-Higuchi plot]

coating system. For $10 \%$ polymer loaded pellets (DSRB-10), the mean dissolution time and $\mathrm{T}_{80}$ was $3.73 \mathrm{~h}$ and $6.79 \mathrm{~h}$ respectively (Table 2), which were few times more than those of the values for the same percent of polymer load (DSRM-10) in matrix system. In case of $15 \%$ polymer load (DSRB-15) the time for $80 \%$ drug release was $\left(\mathrm{T}_{80}\right)$ was $8.26 \mathrm{~h}$ which was about two folds more from the value of formulation DSRM-15 (Table 2). When 5\% polymer was increased more (DSRB-20) the value of mean dissolution time and $\mathrm{T}_{80}$ was increased gradually. About $8.87 \mathrm{~h}$ and $13.7 \mathrm{~h}$ were required to release 50\% and $80 \%$ drug from the coated pellets respectively where as in matrix system (DSRB-20) 80\% drug was released within $6.42 \mathrm{~h}$. So better sustained effect can be achieved if same percent of polymer can be loaded on the pellets as barrier coating system. Also in these cases the release of the drug appeared to follow zero order release kinetics where the correlation coefficient value is $r^{2}>0.98$ (Table 2), which is higher than those of the value of Higuchi's fashion (Table 2 \& Figure 2b). As the drug \& HPMC 6 cps

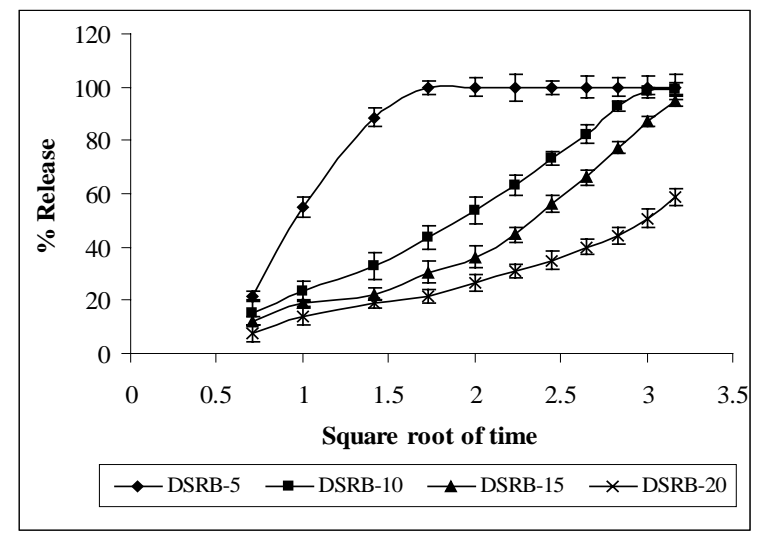

pellets to retard the release of the drug. But in case of 10\%, 15\% \& 20\% ethylcellulose load (DSRB-10, DSRB-15 \& DSRB-20 respectively), from the barrier coating system the drug release increased linearly throughout the whole process (Figure 2a) and seemed to be much more effective to sustain the release of drug. The mean dissolution time and $\mathrm{T}_{80}$ values also increased with the increase in polymer load in barrier were barrier coated with the ethylcellulose so both of the materials get less scope to come to the contact with the dissolution media and channel forming rate of HPMC 6 cps was minimized and ultimately the drug diffusion rate decreased significantly which may lead the sustained effect.

\section{CONCLUSION}

In vitro dissolution study of drug release from the pellets was performed in purified water and the effect of different percents of ethylcellulose load and different ways of manufacturing processes were examined. When drug was loaded with ethylcellulose dispersion (matrix system) it was revealed that there was a minimum effect of ethylcellulose content and below $20 \%$ ethylcellulose load, the polymer failed to give any sustaining effect. Better sustaining effect was found when the drug was loaded with HPMC and coated with $10 \%$ to $20 \%$ ethylcellulose as barrier coating systems. 


\section{ACKNOWLEDGEMENTS}

The authors like to thank Colorcon Asia Pacific Ltd. for Surelease and Eskayef Bangladesh Ltd. $(\mathrm{SK}+\mathrm{F})$ for providing raw materials as well as manufacturing facilities.

\section{REFERENCES}

1. Ghebre-Sellassie, I. 1989. Pellets: A General Overview. In: Pharmaceutical Pelletization Technology. Marcel Dekker Inc., New York, p. 1-3.

2. Special Delivery: Advances in drug therapy.1986. The Research News, University of Michigan. p.1.

3. Cimicata, L. E.1951. How to manufacture and polish smallest pan goods- nonpareil seeds, Confectioners J. 41-43.

4. Tang, L., Schwartz, J.B., Porter, S.C., Schanaare, R.L. and Wigent, R.J. 2000. Drug release from film-coated chlorpheniramine maleate nonpareil beads: effect of watersoluble polymer, coating level, and soluble core material. Pharm. Dev. Tech. 5(3), 383-390.

5. Gohel, M.C. and Panchal, M.K.1999. Formulation optimization of diltiazem $\mathrm{HCl}$ matrix tablets containing modified guar gum using a central composite design. Pharm. Pharmacol. Commun. 5, 331-338.

6. Sanchez-Lafuente, C., Teresa F.M., Fernandez-Arevalo, M., Alvarez-Fuentes, J., Rabasco, A.M. and Mura, P.2002. Development of sustained release matrix tablets of didanosine containing methacrylic and ethylcellulose polymers. Int. J. Pharm. 234(1-2),: 213-221.

7. Ozturk, A., et al. 1990. Mechanism of release from pellets coated with an ethylcellulose - based film. J. controlled Release. 14(3), 203-213.

8. Narisawa, S., et al.1994. Porosity-controlled ethylcellulose film coating. IV. Evaluation of mechanical strength of porous ethylcellulose film. Chem. Pharm. Bull. 42(7), 1491-1495.

9. Bodmeier, R. and Paeratakul, O. 1994. The effect of curing on drug release and morphological properties of ethylcellulose pseudolatex-coated beads. Drug Dev. Ind. Pharm. 20(9), 1517-1533.
10. Iyer, U., et al. 1990. Comparative evaluation of three organic solvent and dispersion-based ethylcellulose coating formulations. Pharmaceut. Technol. 14(9), 68-86.

11. Sarisuta, N. and Sirithunyalug, J. 1988. Release rate of indomethacin from coated granules. Drug Dev. Ind. Pharm. 14, 683-687.

12. Porter, S.C. 1989. Controlled-release film coatings based on ethylcellulose. Drug Dev. Ind. Pharm. 15(10), 1495-1521.

13. Salsa, T., Veiga, F. and Pina, M.E.1997. Oral controlledrelease dosage forms. I. Cellulose ether polymers in hydrophilic matrices. Drug Dev. Ind. Pharm. 23, 929-938.

14. Alderman, D.A. 1984. A review of cellulose ethers in hydrophilic matrices for oral controlled-release dosage forms. Int. J. Pharm. Tech. Prod. Mfr. 5, 1-9.

15. Kent, D., et al. 1978. Solubility studies on ethylcellulose used in film coating. J. Pharm. Pharmacol. 30: 808-810.

16. Rowe, R. 1986. The prediction of compatibility/ incompatibility in blends of ethylcellulose with hydroxypropylmethylcellulose or hydroxypropylcellulose using 2-dimensional solubility parameters maps. J. Pharm. Pharmacol. 38, 214-215.

17. Hogan, J.E. 1989. Hydroxypropyl methylcellulose sustained release technology. Drug Dev. Ind. Pharm. 15(27), 975-999.

18. Sadeghi, F., Ford, J.L., Rubinstein, M.H. and RajabiSiahboomi, A.R. 2000. Study of drug release from pellets coated with Surelease containing hydroxypropyl methylcellulose. Drug Dev. Ind. Pharm. 27(5), 419-430.

19. Saettone, M., et al. 1995. Effect of different polymerplasticizer combinations on in vitro release of theophylline from coated pellets. Int. J. Pharmaceutics. 126, 83-88.

20. Kibbe, H.A. 2000. Handbook of Pharmaceutical Excipients. $3^{\text {rd }}$ Edn., American Pharmaceutical Association and Pharmaceutical Press, p. 195-200.

21. Bamba, M., Puisieusx, F., Marty, J.P. and Carstensen, J.T. 1979. Release mechanisms in gel forming sustained release preparations. Int. J. Pharm. 2, 307-315. 